\title{
Interfacial film stabilized W/O/W nano multiple emulsions loaded with green tea and lotus extracts: systematic characterization of physicochemical properties and shelf-storage stability
}

Tariq Mahmood ${ }^{1,2^{*}}$, Naveed Akhtar $^{1}$ and Sivakumar Manickam³

\begin{abstract}
Background and aims: Multiple emulsions have excellent encapsulating potential and this investigation has been aimed to encapsulate two different plant extracts as functional cosmetic agents in the W/O/W multiple emulsions and the resultant system's long term stability has been determined in the presence of a thickener, hydroxypropyl methylcellulose (HPMC).

Methods: Multiple W/O/W emulsions have been generated using cetyl dimethicone copolyol as lipophilic emulsifier and a blend of polyoxyethylene (20) cetyl ether and cetomacrogol $1000^{\circ}$ as hydrophilic emulsifiers. The generated multiple emulsions have been characterized with conductivity, $\mathrm{pH}$, microscopic analysis, phase separation and rheology for a period of 30 days. Moreover, long term shelf-storage stability has been tested to understand the shelf-life by keeping the generated multiple emulsion formulations at $25 \pm 10^{\circ} \mathrm{C}$ and at $40 \pm 10 \%$ relative humidity for a period of 12 months.
\end{abstract}

Results: It has been observed that the hydrophilic emulsifiers and HPMC have considerably improved the stability of multiple emulsions for the followed period of 12 months at different storage conditions. These multiple emulsions have shown improved entrapment efficiencies concluded on the release rate of conductometric tracer entrapped in the inner aqueous phase of the multiple emulsions.

Conclusion: Multiple emulsions have been found to be stable for a longer period of time with promising characteristics. Hence, stable multiple emulsions loaded with green tea and lotus extracts could be explored for their cosmetic benefits.

Keywords: Green tea, Lotus, Nano, Multiple, Emulsions, Stability

\section{Introduction}

In these days the consumers worldwide are looking for personal care products, in specific the cosmetic products that assure multiple benefits. Besides, they also expect the latest advancements of technology to be incorporated into these innovative product formulations. Facing

\footnotetext{
* Correspondence: tariqmahmood750@gmail.com

'Department of Pharmacy, Faculty of Pharmacy and Alternative Medicine, The Islamia University of Bahawalpur, Bahawalpur 63100, Pakistan

${ }^{2}$ School of Pharmacy, The University of Faisalabad, Faisalabad 37610, Pakistan Full list of author information is available at the end of the article
}

these trends, formulators strive to develop highly differentiated multifunctional product formulations that focus not only on the treatment but also on their aesthetics. A significant number of novel products are available in the markets that have been incorporated with a variety of new generation active ingredients. During the incorporation of these emerging actives, a range of formulation challenges are normally encountered that include control in the stability and the complications of combining several actives into a single cosmetic formulation [1]. Although, multiple emulsions were described in 1925;

\section{Ciomed Central}

(C) 2014 Mahmood et al.; licensee BioMed Central Ltd. This is an Open Access article distributed under the terms of the Creative Commons Attribution License (http://creativecommons.org/licenses/by/2.0), which permits unrestricted use, distribution, and reproduction in any medium, provided the original work is properly credited. The Creative Commons Public Domain Dedication waiver (http://creativecommons.org/publicdomain/zero/1.0/) applies to the data made available in this article, unless otherwise stated. 
but much attention was not given until the report which was published in the late 1960s [2]. Recently, emulsions have established growing interest as vehicles to deliver the drugs efficiently to the body [3] and more importantly cavitation technique has been exploited to generate the nanoemulsions incorporated with the active constituents [4-7].

Complex water-in-oil-in-water (W/O/W) multiple emulsions consist of water-in-oil (W/O) dispersed into the continuous aqueous phase and stabilized with hydrophilic emulsifiers. Due to the unique structure and properties, these multiple emulsions are interesting carrier systems for various drug delivery approaches [8] especially for the controlled release of actives [9]. These multiple emulsions have been generated using cavitation technique [10-13]. In cosmetics, multiple emulsions play an important role to prepare skin care products with prolonged action [1].

However, compared with simple emulsions that consist of only two phases, much more destabilization processes need to be taken into consideration for the multiple emulsions. Four possible processes lead to the instability of $\mathrm{W} / \mathrm{O} / \mathrm{W}$ emulsions (a) coalescence of the internal aqueous droplets (b) coalescence of the oil droplets (c) rupture of the oil film resulting in the loss of the internal aqueous droplets, and (d) passage of water and water-soluble substances between the inner and outer aqueous phases. Thus, for the stabilization of multiple emulsions, following strategies have been proposed; (a) the use of high viscous oils to prevent the diffusion of water and water-soluble substances between the inner and outer aqueous phases, (b) the polymerization of interfacially adsorbed surfactant molecules, and (c) the gelation of oily or aqueous phases of the emulsions [14].

Green tea is among the most important plant extracts unfolded as cosmeceuticals [15] and it is now the subject of focus owing to its proven antioxidant properties and for its ability to repair photo-damage and phototoxicity caused by UV. It is also useful against a variety of skin disorders [16]. Nelumbo nucifera (lotus) extract has been observed to show potent antioxidant and antityrosinase activities and has been found to have higher potential to be further developed as functional cosmetic agent $[17,18]$.

The current study investigates the development of a stable cosmetic multiple emulsion loaded with green tea and lotus extracts which serve as functional cosmetic agents. Moreover, the influence of additives on the resultant aesthetic properties of these multiple emulsions have been investigated by subjecting the multiple emulsions for long term stability under varying conditions of temperature and humidity. Furthermore, it is the first time that a blend of hydrophilic emulsifiers, polyoxyethylene (20) cetyl ether and cetomacrogol $1000^{\circ}$ has been employed in this study.

\section{Materials and methods Materials}

To develop the multiple emulsions, paraffin oil was used as an oil phase (Merck, Germany). The lipophilic emulsifier Abil $^{\odot}$ EM 90 was supplied by Franken (Franken, Germany). Polyoxyethylene (20) cetyl ether (Brij $58^{\circ}$ - Merck, Germany) and Cetomacrogol $1000^{\circ}$ were used as hydrophilic emulsifiers. The thickener used was hydroxypropyl methylcellulose (HPMC, German Grade) and AnalaR grade $\mathrm{MgSO}_{4} \cdot 7 \mathrm{H}_{2} \mathrm{O}$ (BDH, Poole, England) was used as a conductometric tracer. Standardized green tea and lotus extracts were used as functional cosmetic agents to be encapsulated in the inner phase of primary emulsion.

\section{Preparation of extracts}

\section{Extraction of green tea leaves}

$50 \mathrm{~g}$ of grounded and dried green tea leaves were first subjected to a continuous hot extraction process at $80^{\circ} \mathrm{C}$ for $6 \mathrm{~h}$ using a Soxhlet apparatus and by employing 90\% ethanol. A second cycle of extraction with the above-stated conditions was applied for $12 \mathrm{~h}$. A coarse filtration through muslin cloth was followed by a fine filtration (using Whatman Grade No. 1 filter paper). Filtrates were then concentrated in a rotary evaporator at $40^{\circ} \mathrm{C}$ and stored in a refrigerator till further usage.

\section{Extraction of lotus plant}

$100 \mathrm{~g}$ of sacred lotus (whole plant material) was macerated using $2000 \mathrm{ml}$ of $70 \%$ methanol overnight. The macerated mixture was then heated at $60^{\circ} \mathrm{C}$ along with continuous stirring using overhead blade mixer (Eurostar, Germany) at $1000 \mathrm{rpm}$ for $2 \mathrm{~h}$. The resultant mixture was then cooled down and coarse-filtration was carried out using several layers of muslin cloth. Fine filtration was then carried out using Whatman Grade No. 1 filter paper. Filtrates were then concentrated in a rotary evaporator at $40^{\circ} \mathrm{C}$ and then stored in a refrigerator till further usage.

The yield (\%) obtained from both the extractions was calculated by using the following Equation 1,

$$
\text { Yield }(\%)=100\left(\mathrm{~W}_{\mathrm{f}} / \mathrm{W}_{\mathrm{i}}\right)
$$

Where $\mathrm{W}_{\mathrm{i}}$ is the initial weight of the plant material used for extraction and $\mathrm{W}_{\mathrm{f}}$ is the weight of dried extract after solvent evaporation.

\section{DPPH radical scavenging activity}

To measure the DPPH radical scavenging activity of green tea and lotus extracts, the method as reported by Lee and Shibamoto [19] was used. For this, $0.1 \mathrm{mM}$ solution of $\mathrm{DPPH}$ was prepared in ethanol. Then $5 \mu \mathrm{L}$ of the extract was dissolved in DMSO and mixed with ethanolic DPPH solution $(95 \mu \mathrm{L})$. The above mixture was then dispersed in a 96-well microplates reader (Spectra Max plus 384 
Molecular Device, USA) and incubated at $37^{\circ} \mathrm{C}$ for $30 \mathrm{~min}$ and the absorbance was measured at $515 \mathrm{~nm}$. From this, the radical scavenging activity was determined by using the following Equation 2:

$$
\text { DPPH scavenging effect }(\%)=1-(\text { Ac-As } / \text { Ac }) 100
$$

Where $\mathrm{A}_{\mathrm{C}}=$ absorbance of control and $\mathrm{A}_{\mathrm{s}}=$ absorbance of sample

\section{Preparation of multiple emulsions}

Several pre-formulation studies were performed initially using different concentrations of oil and emulsifiers to arrive into a simple emulsion which was then further developed to fine multiple emulsions. Resultant simple emulsions with varying compositions of oil and emulsifier were stored at $40^{\circ} \mathrm{C}$ for a month and each sample was subjected to centrifugation and checked for stability at the end of one month. The most stable simple emulsion resistant to phase separation was then considered for the development of multiple emulsions. In the second stage of development of multiple emulsions, homogenization time and concentration of hydrophilic emulsifiers were varied to obtain a thicker creamy multiple emulsions. The concentration of HPMC was kept constant in all the experiments. The composition of multiple emulsion $(\mathrm{MeC})$ formulations has been shown in Table 1.

All the multiple emulsions have been produced by a two-step emulsification strategy [20]. Briefly, simple emulsion was produced by emulsifying the oil with the lipophilic emulsifier and the mixture was preheated at $75^{\circ} \mathrm{C}$ before the emulsification. Green tea extract and conductometric tracer $\left(\mathrm{MgSO}_{4} .7 \mathrm{H}_{2} \mathrm{O}\right)$ were then incorporated into the internal aqueous phase of the primary emulsion. Mixing of the aqueous phase with the

Table 1 Composition of HPMC thickened green tea and lotus extracts loaded multiple emulsions (MeC) (\% w/w)

\begin{tabular}{ll}
\hline Primary emulsion (W/O) & 24 \\
\hline Paraffin oil & 4.25 \\
Cetyl dimethicone copolyol & 2.5 \\
Green tea extract & 2.5 \\
Lotus extract & 0.7 \\
Magnesium sulfate & 100 \\
Deionized water (Q.S) & \\
Multiple emulsion (W/O/W) & 80 \\
Primary emulsion & 3.75 \\
Polyoxyethylene (20) cetyl ether & 2.5 \\
Cetomacrogol 1000 & 1.25 \\
Hydroxypropyl methylcellulose (HPMC) & 100 \\
Deionized water (Q.S) &
\end{tabular}

oil phase continued at $2000 \mathrm{rpm}$ for $15 \mathrm{~min}$ and then at $1000 \mathrm{rpm}$ for $10 \mathrm{~min}$. Finally the obtained emulsion was cooled down to room temperature while maintaining a mixing speed of $500 \mathrm{rpm}$ for a further $10 \mathrm{~min}$. Mixing was accomplished by IKA Mixing Overhead Stirrer (Eurostar, Germany). For the second stage emulsification, the simple emulsion was added to the aqueous phase containing hydrophilic emulsifier at room temperature. A stirring speed of $700 \mathrm{rpm}$ was maintained until the formation of multiple emulsion which was confirmed by microscopic analysis.

\section{Stability studies}

In this study the focus is on the emulsion stability and not on the release behavior as the emulsion is designed to be spread on the skin and rubbing will aid in the release of active compounds. For the stability studies, multiple emulsions were weighed (50 g) and packed in glass containers with $100 \mathrm{~g}$ capacity and were kept in the incubation chambers at different storage temperature for a period of 30 days (accelerated storage period). Different storage conditions that were applied: room temperature $\left(25 \pm 1^{\circ} \mathrm{C}\right)$, low temperature $\left(8 \pm 1^{\circ} \mathrm{C}\right)$, high temperature $\left(40 \pm 1^{\circ} \mathrm{C}\right)$ and high temperature with humidity $\left(40 \pm 1^{\circ} \mathrm{C}\right.$ with $75 \%$ relative humidity). At the pre-determined intervals ( 24 h, 48 h, 7 d, 15 d and 30 d, 8 months and 12 months), samples were removed from the storage and allowed to reach to room temperature $\left(25^{\circ} \mathrm{C}\right)$ prior to evaluating their physico-chemical characteristics.

\section{Characterization of multiple emulsions $(\mathrm{MeC})$}

After the preparation of multiple emulsions $(\mathrm{MeC})$ they were characterized by different physico-chemical parameters such as microscopic analysis, conductivity, $\mathrm{pH}$, phase separation and rheology for a follow-up period of 30 days and the influence of different storage conditions on these parameters were also determined. Initially the formulation samples $(\mathrm{MeC})$ were stored at $8^{\circ} \mathrm{C}, 25^{\circ} \mathrm{C}$, $40^{\circ} \mathrm{C}$ and at $40^{\circ} \mathrm{C}$ with $75 \%$ relative humidity. Also, one sample was kept in a plastic container and the stability was followed for 12 months at $25 \pm 10^{\circ} \mathrm{C}$ with $40 \pm 10 \%$ relative humidity.

\section{Microscopic analysis}

The microscopic analysis of the generated multiple emulsions were examined using an optical microscope (Nikon E200, Nikon, Japan) with a camera (DCM-35 USB 2.0 and Minisee Image software). Observations were made at $100 \mathrm{X}$ magnification after diluting the multiple emulsions. Measurements of 100 droplets per sample per storage condition were performed. The obtained images were analyzed using the software Digimizer (Version 4.1.1.0, MedCalc Software, Mariakerke, Belgium). After calculating the droplet diameter, the coefficient 
of variation $(\mathrm{CV})$ was calculated by using the following Equation 3:

$$
\begin{aligned}
\mathrm{CV}(\%)= & {[\text { standard deviation }(\mu \mathrm{m})} \\
& / \text { mean droplet diameter }(\mu \mathrm{m})] 100
\end{aligned}
$$

\section{Conductometric analysis}

Conductometric analysis of the undiluted multiple emulsion was performed to examine the release of the electrolyte that has been initially entrapped in the internal aqueous phase. The specific conductivity of the emulsions was directly measured by using a digital conductivity meter (WTW- Tetracon ${ }^{\circ}$, Germany) at $25 \pm 2^{\circ} \mathrm{C}$. Conductivity tests were performed for the multiple emulsion formulations immediately after their preparation and after $24 \mathrm{~h}, 7 \mathrm{~d}, 15 \mathrm{~d}, 30 \mathrm{~d}, 8$ months and 12 months that have been kept at different storage conditions.

\section{$\mathrm{pH}$ determination}

The $\mathrm{pH}$ of fresh multiple emulsion formulations and the formulations kept at different storage conditions was determined by using a digital $\mathrm{pH}$ meter (ProfiLine $\mathrm{pH}$ 197, WTW, Germany). The $\mathrm{pH}$ measurements were also taken for the formulations after $24 \mathrm{~h}, 7 \mathrm{~d}, 15 \mathrm{~d}, 30 \mathrm{~d}$, 8 months and 12 months.

\section{Centrifugation}

The generated multiple emulsions were centrifuged at $25^{\circ} \mathrm{C}$ (12) (Hettich EBA 20, Germany) and at $5000 \mathrm{rpm}$ for $20 \mathrm{~min}$. Centrifugation of each formulation was performed after 24 h, $7 \mathrm{~d}, 15 \mathrm{~d}, 30 \mathrm{~d}, 8$ months and 12 months that have been kept at different storage conditions.

\section{Rheological examination}

The rheological properties and viscosity measurements of multiple emulsions were determined using a Brookfield programmable rheometer (Model DV.III; Brookfield engineering laboratories Inc. USA). Rheocalc V 3.2 (Microsoft Corporation) software was used as a supporting program during the measurements. $0.5 \mathrm{~g}$ of each of the formulation was weighed and the viscosities were determined at $25^{\circ} \mathrm{C}$ with spindle speeds ranging from 100 to $200 \mathrm{rpm}$ by using a spindle CP 41.

\section{Thermal stress test with repeated centrifugation}

After one month of testing under accelerated conditions, one sample was packed in a plastic container and monitored for 12 months at varying conditions of $25 \pm 10^{\circ} \mathrm{C}$ with $40 \pm 10 \%$ relative humidity. The above-mentioned conditions are very close to the change in the environmental conditions of Pakistan. The samples after 8 and 12 months were then subjected to three elevated temperatures i.e. $50^{\circ} \mathrm{C}, 60^{\circ} \mathrm{C}$ and $80^{\circ} \mathrm{C}$ for $30 \mathrm{~min}$ in a thermostated water bath (Model H-4, China). In the first sequence, three $1 \mathrm{ml}$ samples taken in plastic tubes (Eppendorf) were heated at three different temperatures i.e. $50^{\circ} \mathrm{C}, 60^{\circ} \mathrm{C}$ and $80^{\circ} \mathrm{C}$ for $30 \mathrm{~min}$, and at the end they were centrifuged at $5000 \mathrm{rpm}$ for $20 \mathrm{~min}$ and observed for the presence of any phase separation. In the second sequence, one sample filled in the tube was subjected to $50^{\circ} \mathrm{C}$ for $30 \mathrm{~min}$ and centrifuged again to observe the presence of any phase separation. The sample that was subjected to $50^{\circ} \mathrm{C}$ confirmed the absence of separation which was then subjected to the next elevated temperature i.e. $60^{\circ} \mathrm{C}$ and centrifuged to detect any phase separation. It showed no phase separation at $60^{\circ} \mathrm{C}$, which was then finally subjected to $80^{\circ} \mathrm{C}$ to detect any phase separation. After each stage of heating and centrifugation, samples were observed under the microscope to confirm the integrity of the globules of multiple emulsions. Before subjecting to thermal stress testing, $\mathrm{pH}$ and conductivity measurements were performed for the samples of 8 and 12 months to investigate the effect of varying environmental conditions on the above parameters.

\section{Results and discussion \\ Antioxidant activity}

The extraction yield was first determined on the basis of dry plant material used for extraction and then the antioxidant potential of both the plant extracts was determined. From the results, a stronger antioxidant activity has been found out from the green tea extract while lotus extract has shown a less potent antioxidant activity as compared to green tea extract. Previous studies confirmed that the antioxidant activity of crude extract of green tea is higher than that of the standard antioxidant, ascorbic acid [21]. Also, earlier reports established that the methanolic extract of lotus has lower activity as compared to BHA and ascorbic acid [22]. Similar to above studies, the green tea in our study has shown a stronger antioxidant activity than lotus, irrespective of the extraction yield of green tea that has been found to be much lower than lotus extract. Table 2 shows the antioxidant activities and the extraction yield obtained from these two extracts.

\section{Microscopic analysis and centrifugation}

Microscopic analysis is a useful and informative tool to understand the characteristics of multiple emulsions. Further, droplet size measurements indicate the stability of multiple emulsions as a faster increase in the droplet size with time is the indicator of lower stability of

Table 2 Antioxidant activities and the extraction yield of green tea and lotus extracts

\begin{tabular}{lll}
\hline Extract & DPPH radical scavenging activity (\%) & Yield (\%) \\
\hline Green tea & $88 \pm 0.2$ & 2.1 \\
Lotus & $75 \pm 0.41$ & 4.15 \\
\hline
\end{tabular}


the system [23]. The characteristics of multiple emulsions were investigated at the formulation stage as well as for the followed 30 days at different conditions of storage i.e. $8^{\circ} \mathrm{C}, 25^{\circ} \mathrm{C}, 40^{\circ} \mathrm{C}$ and at $40^{\circ} \mathrm{C}$ with $75 \%$ relative humidity. Furthermore, multiple emulsions were subjected to extensive centrifugation at $5000 \mathrm{rpm}$ for $20 \mathrm{~min}$ to accelerate the phase separation of the system for the followed-up period of 12 months to understand the stability.

No phase separation was observed in any of the samples upon extensive centrifugation. Mean globule size was in the range of $8.41 \pm 3 \mu \mathrm{m}$ to $10.81 \pm 7 \mu \mathrm{m}$ (mean \pm standard deviation). The sample that was kept at $8^{\circ} \mathrm{C}$ has shown smaller size of globules while an increase in the globule size was observed with an increase in the storage temperature. A maximum increase in the globule size was observed at $40^{\circ} \mathrm{C}$. However this increase in the globule size with temperature does not seem to be a significant as the coefficient of variation $(\mathrm{CV})$ was only varying in a narrow range at all the studied storage temperatures. A larger CV indicates an unacceptable limit of shrinkage or coalescence of the globules which indicate a lack of uniformity of globules. As reported earlier, an increase in the globule size is due to coalescence phenomena, while a decrease in the size is due to leakage of water from the internal to the external aqueous phase [24]. Results from the microscopic and centrifugation stability studies have been shown in Tables 3, 4 and 5 . Photomicrographs of multiple emulsion formulations that have been kept at different storage conditions have been shown in Figure 1.

\section{Conductometric and $\mathrm{pH}$ analysis}

Incorporating a conductometric tracer in the inner aqueous phase of the primary emulsion is necessary to detect any leakage from the internal to the external aqueous phase of $\mathrm{W} / \mathrm{O} / \mathrm{W}$ emulsion. Measurement of conductivity also provides the information about the entrapment of active substances in the primary emulsion. The amount of release is directly proportional to the amount of active substance that is available in the external aqueous phase and a rapid release therefore does not favor the slow release of the active substance. No significant variation in the conductivity was observed over 30 days of storage period and at any of the temperature that was subjected

Table 3 Mean globule size and coefficient of variation (CV) of multiple emulsions followed for 30 days

\begin{tabular}{llll}
\hline Conditions & $\begin{array}{l}\text { Multiple droplets } \\
(\boldsymbol{\mu m})\end{array}$ & $\begin{array}{l}\text { Inner droplets } \\
(\mathbf{n m})\end{array}$ & CV (\%) \\
\hline $8^{\circ} \mathrm{C}$ & $8.05 \pm 4.2$ & $800 \pm 20$ & 0.53 \\
$25^{\circ} \mathrm{C}$ & $8.92 \pm 4.2$ & $1200 \pm 60$ & 0.47 \\
$40^{\circ} \mathrm{C}$ & $10.81 \pm 7.0$ & $1400 \pm 50$ & 0.65 \\
$40^{\circ} \mathrm{C}$ with 75\% RH & $10.50 \pm 5.5$ & $1400 \pm 80$ & 0.53 \\
\hline
\end{tabular}

Table 4 Conductivity, pH and centrifugation stability of multiple emulsions kept at different storage conditions for 30 days

\begin{tabular}{|c|c|c|c|c|}
\hline & $8^{\circ} \mathrm{C}$ & $25^{\circ} \mathrm{C}$ & $40^{\circ} \mathrm{C}$ & $40^{\circ} \mathrm{C}$ with $75 \% \mathrm{RH}$ \\
\hline \multicolumn{5}{|c|}{$\mathrm{pH}^{*}$} \\
\hline $24 \mathrm{~h}$ & $5.00 \pm 0.09$ & $5.19 \pm 0.20$ & $4.99 \pm 0.18$ & $4.99 \pm 0.07$ \\
\hline $7 \mathrm{~d}$ & $4.97 \pm 0.14$ & $5.14 \pm 0.07$ & $4.91 \pm 0.09$ & $4.95 \pm 0.10$ \\
\hline $15 \mathrm{~d}$ & $4.92 \pm 0.15$ & $5.12 \pm 0.02$ & $4.90 \pm 0.10$ & $4.93 \pm 0.07$ \\
\hline $30 \mathrm{~d}$ & $5.35 \pm 0.06$ & $5.05 \pm 0.04$ & $5.12 \pm 0.12$ & $4.99 \pm 0.12$ \\
\hline \multicolumn{5}{|c|}{ Conductivity** } \\
\hline $24 \mathrm{~h}$ & $76.40 \pm 1.90$ & $76.37 \pm 1.19$ & $66.50 \pm 1.80$ & $63.53 \pm 1.51$ \\
\hline $7 d$ & $83.30 \pm 1.37$ & $85.90 \pm 3.90$ & $77.50 \pm 1.71$ & $69.83 \pm 3.00$ \\
\hline $15 d$ & $84.27 \pm 1.32$ & $89.87 \pm 1.90$ & $79.20 \pm 3.30$ & $74.20 \pm 2.08$ \\
\hline $30 d$ & $89.17 \pm 2.80$ & $57.73 \pm 2.14$ & $93.00 \pm 1.20$ & $60.30 \pm 2.39$ \\
\hline \multicolumn{5}{|c|}{ Centrifugation stability*** } \\
\hline $24 \mathrm{~h}$ & $S$ & $S$ & S & $S$ \\
\hline $7 d$ & $S$ & $S$ & $S$ & $S$ \\
\hline $15 d$ & $S$ & $S$ & $S$ & $S$ \\
\hline $30 d$ & S & S & S & $S$ \\
\hline
\end{tabular}

to. These results reveal that conductometric tracer has not diffused or rupturing of oil layer did not occur over the followed period of 30 days. In general it is believed that during the storage conductivity increases due to i) diffusion of an electrolyte, ii) the coalescence of globules iii) destruction of oil film because of the osmotic pressure and the leakage of internal aqueous phase [25].

Table 5 Physicochemical characteristics of multiple emulsions shelf-stored at 8 and 12 months and subjected to thermal stress test with and without repeated centrifugation

\begin{tabular}{|c|c|c|c|}
\hline & $50^{\circ} \mathrm{C}$ & $60^{\circ} \mathrm{C}$ & $80^{\circ} \mathrm{C}$ \\
\hline \multicolumn{4}{|l|}{ After 8 months } \\
\hline \multicolumn{4}{|l|}{${ }^{*}$ Centrifugation stability } \\
\hline Samples without repeated heating & $\mathrm{S}$ & $\mathrm{s}$ & S \\
\hline Sample with repeated heating & $S$ & $S$ & S \\
\hline \multicolumn{4}{|l|}{ Microscopic globule integrity } \\
\hline Samples without repeated heating & $S$ & $S$ & S \\
\hline Sample with repeated heating & $\mathrm{S}$ & S & S \\
\hline \multicolumn{4}{|l|}{ After 12 months } \\
\hline \multicolumn{4}{|l|}{${ }^{*}$ Centrifugation stability } \\
\hline Samples without repeated heating & $S$ & S & S \\
\hline Sample with repeated heating & $S$ & S & $S$ \\
\hline \multicolumn{4}{|l|}{ Microscopic globule integrity } \\
\hline Samples without repeated heating & $S$ & S & $S$ \\
\hline Sample with repeated heating & $\mathrm{S}$ & $\mathrm{S}$ & $\mathrm{S}$ \\
\hline
\end{tabular}

${ }^{*}$ Centrifugation at $5000 \mathrm{rpm}$ for $20 \mathrm{~min}$ for each sample, $\mathrm{S}=$ Stable. 


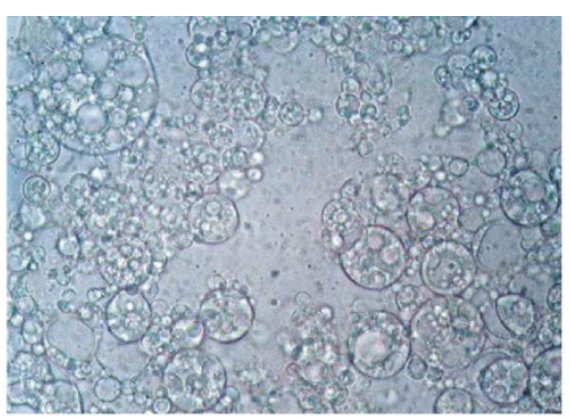

(A)

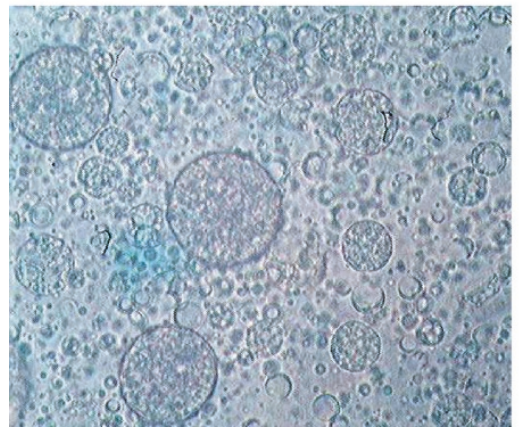

(B)

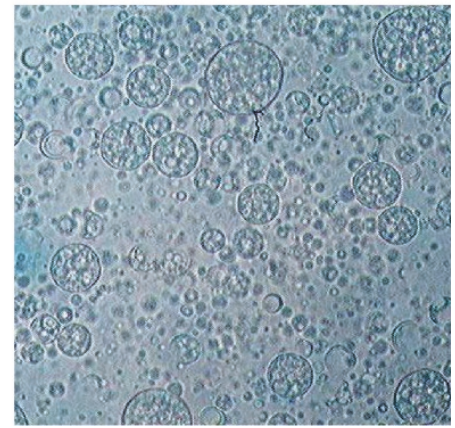

(C)

Figure 1 Photomicrographs of multiple emulsion formulations kept at different storage conditions for 12 months. A=Fresh sample, B = After 8 months, $\mathbf{C}=$ After 12 months.

Conductivity values for the first 30 days decreased for the formulation that was kept at $40^{\circ} \mathrm{C}$ with $75 \% \mathrm{RH}$ relative to the conductivity values of the fresh sample. This may be due to the formation of larger droplet size or phase separation. But no phase separation was observed at this condition. However, an increase in the droplet size was observed. A similar justification has been offered previously [26] where the reduction in the observed conductivities has been attributed to phase separation and larger droplet size. After 8 and 12 months of storage, conductivity values $(51.7 \pm 3.06,29.3 \pm 0.30$ respectively) tend to decrease but yet no phase separation occurred even after heating the samples at $80^{\circ} \mathrm{C}$. Normal $\mathrm{pH}$ of skin is in between 5 and 6 , and 5.5 is considered to be the average $\mathrm{pH}$ of skin [27]. Results of our $\mathrm{pH}$ analysis indicate that there is no variation in the $\mathrm{pH}$ of multiple emulsions kept at different conditions of storage and even after 8 and 12 months of storage ( $5.4 \pm 0.01,5.6 \pm 0.01$ respectively) under varying temperature and humidity conditions. Results of this study (Table 4) indicate that different storage conditions did not have any influence on the $\mathrm{pH}$ and conductivity.

\section{Thermal stress test with repeated centrifugation}

Thermal stress test with repeated centrifugation has been applied on multiple emulsions to study the stability of these emulsions under extensive stress conditions of temperature change and centrifugal force. The obtained results of this test have been shown in Table 5 .

Obviously the generated multiple emulsions found to be extremely stable against elevated temperatures and the thermal stress could not produce any change in the globule integrity, phase inversion or phase separation. Even when the multiple emulsion was subjected to elevated temperatures and repeated centrifugation at $5000 \mathrm{rpm}$ for $20 \mathrm{~min}$, no phase separation was observed and globules have been found to be intact as observed through microscopic examinations. Hence, when the emulsion was tested after 12 months of storage at $25 \pm 10^{\circ} \mathrm{C}$ with $40 \pm 10 \%$ relative humidity it was found to be very stable and expected not to deteriorate soon. This resistance to phase separation appears due to the addition of Cetomacrogol $1000^{\circ}$, which acts as a film stabilizer and this has not been reported so far. The possible mechanism behind Cetomacrogol $1000^{\circ}$ as film stabilizer is probably due to its self-bodying action in which rheological properties of the emulsions are related to gel networks formed in the continuous phases. This phenomenon has been presented previously when mixtures of emulsifiers of the surfactant-fatty alcohol type are used to stabilize oil in water emulsions $[28,29]$.

\section{Rheological analysis}

Consistency of cosmetic formulations is a very important aspect and is determined by the rheological methods. 


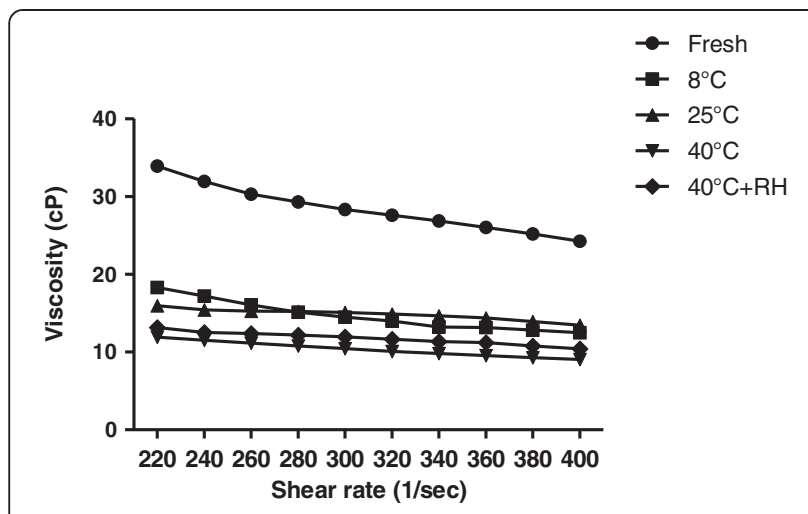

Figure 2 Viscosities of fresh sample and the samples kept at different conditions of storage for $\mathbf{3 0}$ days.

Varying shear rates were applied to multiple emulsions to determine the flow parameters, while fitting the data in power law equation 4 :

$$
\mathrm{\tau}=\mathrm{K} \gamma^{\mathrm{n}}
$$

Where $\tau$ is the shear stress, $\gamma$ is the shear rate, $K$ is the consistency index and $\mathrm{n}$ is the flow behavior index.

Consistency index $\mathrm{K}$ is a measure of the system consistency and it is related to apparent viscosity. Flow behavior index $n$ determines the degree of non-newtonian flow behavior and varies in the range between 0 and 1 . The non-newtonian behavior of the investigated system is more pronounced for smaller values of " $n$ ". We measured the viscosities of multiple emulsions at a speed of 100 to $200 \mathrm{rpm}$ while applying the shear rates from 200 to 400 on each of the samples. Varying shear rates were applied for the quality assurance of emulsions under stress conditions. Results for the rheology of fresh sample and for the samples that have been kept at different conditions of storage (followed for 30 days) have been shown in Figure 2.

Samples of multiple emulsions revealed non-newtonian flow and shear thinning behavior with different conditions of storage upon varying the shear rate. With an increase in shear rate and shear stress, a decrease in viscosity could be observed. Rheological analysis revealed excellent fits and were found to be from 98.6 to 99.6 and the obtained values of $K$ and $n$ have been shown in Table 6. It could be seen that all the samples exhibited pseudo-plastic

Table 6 Rheological analysis followed for 30 days

\begin{tabular}{llllll}
\hline & Initial & $\mathbf{8}^{\circ} \mathbf{C}$ & $\mathbf{2 5}^{\circ} \mathbf{C}$ & $\mathbf{4 0}^{\circ} \mathbf{C}$ & $\mathbf{4 0}^{\circ} \mathbf{C} \mathbf{R H}^{*}$ \\
\hline Consistency index (CP) & 454.4 & 435.3 & 119.3 & 52.5 & 75.1 \\
Flow index & 0.51 & 0.40 & 0.57 & 0.78 & 0.67 \\
Confidence of fit (\%) & 99.3 & 98.6 & 99.6 & 98.6 & 99 \\
\hline
\end{tabular}

$\mathrm{RH}^{*}=$ Relative humidity. behavior with the flow behavior index ( $\mathrm{n}$ ) between 0.40 and 0.78. At higher temperatures, samples exhibited low consistency and thus a moderate shifting towards newtonian behavior.

\section{Conclusion}

Fascination towards novel topical formulations loaded with functional actives having better antioxidant activity have emerged in the recent era. Encapsulation has been carried out with plant extracts (5\%) in W/O/W multiple emulsion that have been fabricated using different emulsifiers. Promising stability characteristics have been observed in the generated multiple emulsions that were kept under different storage conditions. More importantly, multiple emulsions kept at different storage conditions were stable toward any phase separation followed for the 12 months i.e. accelerated and under shelf-storage. Globule size remained constant at different storage conditions. In addition, the coefficient of variation was lower enough to speculate that there was no internal deformation in the multiple emulsion characteristics. Conductivity analysis revealed that entrapment efficiency of multiple emulsions was excellent enough to offer sustained release of bio-functional agents. Rheological analysis revealed excellent curve fittings for all the formulations and the formulations subjected to elevated temperatures showed shifting toward newtonian behavior. Based on the above observations, it is expected that the green tea and lotus extracts loaded multiple emulsions could be excellent carrier of these powerful antioxidant substances ensuring long term stability of actives.

\section{Competing interests}

The authors declare that they have no competing interests.

\section{Authors' contributions}

All the authors have contribution in the design, planning and carrying out the experiments as well as drafting the manuscript. All the authors have read and approved the final manuscript.

\section{Acknowledgments}

The authors highly obliged for the financial support by Higher Education Commission of Pakistan.

\section{Author details}

'Department of Pharmacy, Faculty of Pharmacy and Alternative Medicine, The Islamia University of Bahawalpur, Bahawalpur 63100, Pakistan. ${ }^{2}$ School of Pharmacy, The University of Faisalabad, Faisalabad 37610, Pakistan.

${ }^{3}$ Manufacturing and Industrial Processes Research Division, Faculty of Engineering, University of Nottingham Malaysia Campus, Jalan Broga, Semenyih 43500, Malaysia.

Received: 13 December 2013 Accepted: 29 April 2014

Published: 12 May 2014

\section{References}

1. Patravale VB, Mandawgade SD: Novel cosmetic delivery systems: an application update. Int J Cosmet Sci 2008, 30:19-33.

2. Hino T, Kawashima Y, Shimabayashi S: Basic study for stabilization of w/o/w emulsion and its application to transcatheter arterial embolization therapy. Adv Drug Deliv Rev 2000, 45:27-45. 
3. Rasul A, Akhtar N: Formulation and in-vivo evaluation for anti-aging effects of an emulsion containing basil extract using non- invasive biophysical techniques. DARU 2011, 19(5):344-350.

4. Tang SY, Manickam S: Design and evaluation of aspirin-loaded water-in-oil-water nano multiple emulsions prepared using two-step ultrasonic cavitational emulsification technique. Asia-Pac J Chem Eng 2012, 7(S1):S145-S156.

5. Tang SY, Manickam S, Ng AM, Shridharan P: Anti-inflammatory and analgesic activity of novel oral aspirin-loaded nanoemulsion and nano multiple emulsion formulations generated using ultrasound cavitation. Int J Pharm 2012, 430:299-306.

6. Tang SY, Manickam S: A novel and facile liquid whistle hydrodynamic cavitation reactor to produce submicron multiple emulsions. AlChEJ 2013, 59(1):155-167.

7. Tang SY, Manickam S, Billa N: Impact of osmotic pressure and gelling in the generation of highly stable single core water-in-oil-in-water (W/O/W) nano multiple emulsions of aspirin assisted by two-stage ultrasonic cavitational emulsification. Colloids Surf B Biointerfaces 2013, 102:653-658.

8. Schmidts T, Dobler D, Nissing C, Garn H, Runkel F: Development of multiple w/o/w emulsions as dermal carrier system for oligonucleotides: Effect of additives on emulsion stability. Int J Pharm 2010, 398:107-113.

9. Mishra B, Sahoo BL, Mishra M, Shukla D, Kumar V: Design of a controlled release liquid formulation of lamotrigine. DARU 2011, 19(2):126-137.

10. Tang SY, Sivakumar M, Wei TK, Billa N: Formulation development and optimization of a novel cremophore EL-based nanoemulsion using ultrasound cavitation. Ultrason Sonochem 2012, 19(2):330-45.

11. Wei TK, Sivakumar M: Response surface methodology, an effective strategy in the optimisation of the generation of curcumin-loaded micelles. Asia-Pac J Chem Eng 2012, 7(S1):S125-S133.

12. Parthasarathy S, Tang SY, Sivakumar M: Generation and optimization of palm oil based oil-in-water $(\mathrm{O} / \mathrm{W})$ nanoemulsions and nanoencapsulation of curcumin using liquid whistle hydrodynamic cavitation reactor (LWHCR). Ind Eng Chem Res 2013, 52(34):11829-11837.

13. Tang SY, Parthasarathy S, Sivakumar M: Impact of process parameters in the generation of novel aspirin nanoemulsions - Comparative studies between ultrasound cavitation and microfluidiser. Ultrason Sonochem 2013, 20(1):485-497.

14. Schmidts T, Dobler D, Nissing C, Garn H, Runkel F: Influence of hydrophilic surfactants on the properties of multiple W/O/W emulsions. J Colloid Interface Sci 2009, 338:184-192.

15. Preetha JP, Karthika K: Cosmeceuticals - An evolution. Int J ChemTech Res 2009, 1(4):1217-1223.

16. Aburjai T, Natsheh FM: Plants used in cosmetics. Phytother Res 2003, 17:987-1000.

17. Srichayanurak C, Phadungkit M: Antityrosinase and antioxidant activities of selected Thai herbal extracts. KKU Res J 2008, 13(6):673-676.

18. Kim T, Kim HJ, Cho SK, Kang WY, Baek H, Jeon HY, Kim B, Kim D: Nelumbo nucifera extract as skin whitening and anti-wrinkle cosmetic agent. Korean J of Chem Eng 2011, 28(1):424-427.

19. Lee K, Shibamoto T: Antioxidant property of aroma extract isolated from clove bud [syzygiun aromaticum (L.) Merr. Et Perry]. Food Chem 2001, 74:443-448

20. Akhtar N, Ahmad M, Khan HMS, Akram J: Gulfishan, Mahmood A, Uzair M. Formulation and characterization of a multiple emulsion containing 1\% L-ascorbic acid. B Chem Soc Ethiopia 2010, 24:1-10.

21. Khalaf NA, Shakya AK, Al-Othman A, El-Agbar Z, Farah H: Antioxidant activity of some common plants. Turk J Bio 2008, 32:51-55.

22. Wang $L$, Yen J-H, Liang H-L, Wu M-J: Antioxidant effect of methanol extracts from lotus plumule and blossom (Nelumbo nucifera Gertn.). J Food Drug Anal 2003, 11:60-66

23. Bernardi DS, Pereira TA, Maciel NR, Bortoloto J, Viera GS, Oliveira GC, Rocha-Filho PA: Formation and stability of oil-in-water nanoemulsions containing rice bran oil: in-vitro and in-vivo assessments. J Nanobiotechnol 2011, 9(44):1-9.

24. Tirnaksiz F, Kalsin O: A topical w/o/w multiple emulsions prepared with Tetronic 908 as a hydrophilic surfactant: Formulation, characterization and release study. J Pharm Pharm Sci 2005, 8:299-315.

25. Pays K, Giermanska-Kahn J, Pouligny B, Bibette J, Leal-Calderon F: Double emulsions: How does release occur? J Control Release 2002, 79:193-200.
26. Kantarci G, Ozgüney I, Karasulu HY, Arzik S, Güneri T: Comparison of different water/oil microemulsions containing diclofenac sodium: preparation, characterization, release rate, and skin irritation studies. AAPS PharmSciTech 2007, 2(8):E91.

27. Akhtar N, Ahmad M, Gulfishan, Masood MI: Formulation and in-vitro evaluation of a cosmetic emulsion from almond oil. Pak J Pharm Sci 2008, 21:430-437.

28. Barry BW, Saunders GM: Rheology of systems containing cetomacrogol 1000 — cetostearyl alcohol. I. Self-bodying action. J Colloid Interface Sci 1972, 38(3):616-625.

29. Barry BW: The control of oil-in-water emulsion consistency using mixed emulsifiers. J Pharma Pharmacol 1969, 21:533-540.

\section{doi:10.1186/1477-3155-12-20}

Cite this article as: Mahmood et al.: Interfacial film stabilized W/O/W nano multiple emulsions loaded with green tea and lotus extracts: systematic characterization of physicochemical properties and shelf-storage stability. Journal of Nanobiotechnology 2014 12:20.

\section{Submit your next manuscript to BioMed Central and take full advantage of:}

- Convenient online submission

- Thorough peer review

- No space constraints or color figure charges

- Immediate publication on acceptance

- Inclusion in PubMed, CAS, Scopus and Google Scholar

- Research which is freely available for redistribution 